\title{
Prevalent Vertebral Deformity Predicts Incident Hip though not distal Forearm Fracture: Results from the European Prospective Osteoporosis Study
}

A. A. Ismail ${ }^{1}$, W. Cockerill ${ }^{1}$, C. Cooper ${ }^{2}$, J. D. Finn ${ }^{1}$, K. Abendroth ${ }^{3}$, G. Parisi ${ }^{4}$, D. Banzer ${ }^{5}$, L. I. Benevolenskaya ${ }^{6}$, A. K. Bhalla ${ }^{7}$, J. Bruges Armas ${ }^{8}$, J. B. Cannata ${ }^{9}$, P. D. Delmas ${ }^{10}$, J. Dequeker ${ }^{11}$, G. Dilsen ${ }^{12}$, R. Eastell ${ }^{13}$, O. Ershova ${ }^{14}$, J. A. Falch ${ }^{15}$, B. Felsch ${ }^{3}$, S. Havelka ${ }^{16}$, K. Hoszowski ${ }^{17}$, I. Jajic ${ }^{18}$, U. Kragl $^{19}$, O. Johnell ${ }^{20}$, A. Lopez $\mathrm{Vaz}^{21}$, R. Lorenc ${ }^{17}$, G. Lyritis ${ }^{22}$, F. Marchand ${ }^{23}$, P. Masaryk ${ }^{24}$, C. Matthis ${ }^{25}$, T. Miazgowski ${ }^{26}$, H. A. P. Pols ${ }^{27}$, G. Poor ${ }^{28}$, A. Rapado ${ }^{29}$, H. H. Raspe ${ }^{25}$, D. M. Reid ${ }^{30}$, W. Reisinger ${ }^{31}$, J. Janott ${ }^{32}$, C. Scheidt-Nave ${ }^{33}$, J Stepan ${ }^{34}$, C. Todd ${ }^{35}$, K. Weber ${ }^{36}$, A. D. Woolf ${ }^{37}$, G. Ambrecht ${ }^{38}$, W. Gowin ${ }^{38}$, D. Felsenberg ${ }^{38}$, M. Lunt ${ }^{1}$, J. A. Kanis ${ }^{39}$, J. Reeve ${ }^{35}$, A. J. Silman ${ }^{1}$ and T. W. O’Neill ${ }^{1}$

${ }^{1}$ ARC Epidemiology Unit, University of Manchester, Manchester, UK; ${ }^{2}$ University of Southampton, Southampton General Hospital, Southampton, UK; ${ }^{3}$ Clinic for Internal Medicine, Jena, Germany; ${ }^{4}$ Institute of Clinical Medicine, University of Siena, Siena, Italy; ${ }^{5}$ Behring Hospital, Berlin, Germany; ${ }^{6}$ Institute of Rheumatology, Moscow, Russia; ${ }^{7}$ Royal National Hospital for Rheumatic Diseases, Bath, UK; ${ }^{8}$ Hospital de Angra do Heroismo, Azores, Portugal; ${ }^{9}$ Asturia General Hospital, Oviedo, Spain; ${ }^{10}$ Hôpital Edouard Herriot, Lyon, France; ${ }_{11}^{11}$ Rheumatology Unit, University Hospital, Leuven, Belgium; ${ }^{12}$ Medical Faculty, University of Istanbul, Istanbul, Turkey; ${ }^{13}$ Bone Metabolism Group, Northern General Hospital, Sheffield, UK; ${ }^{14}$ Medical Institute, Yaroslavl, Russia; ${ }_{15}^{15}$ Aker Hospital, Oslo, Norway; ${ }^{16}$ Institute of Rheumatology, Prague, Czech Republic; ${ }^{17}$ PKP Hospital, Warsaw, Poland; ${ }^{18}$ Clinical Hospital, Zagreb, Croatia; ${ }^{19}$ Medical Academy, Erfurt, Germany; ${ }^{20}$ Malmö University Hospital, Malmö, Sweden; ${ }^{21}$ Hospital de San Joao, Oporto, Portugal; ${ }^{22}$ Laboratory for the Research of Musculoskeletal System, University of Athens, Athens, Greece; ${ }^{23}$ Centre de Medecine Specialisée, Montceau-les-Mines, France; ${ }^{24}$ Institute of Rheumatic Diseases, Piestany, Slovakia; ${ }^{25}$ Institute of Social Medicine, Lubeck, Germany; ${ }^{26}$ Academy of Medicine, Szczecin, Poland; ${ }^{27}$ Department of Epidemiology and Department of Internal Medicine, Erasmus University, Rotterdam, Netherlands; ${ }^{28}$ National Institute of Rheumatology and Physiotherapy, Budapest, Hungary; ${ }^{29}$ Faculty of Medicine, University of Madrid, Madrid, Spain; ${ }^{30}$ Department of Medicine and Therapeutics, University of Aberdeen, UK; ${ }^{31}$ Institute for Diagnostic Radiology, Humboldt University, Berlin, Germany; ${ }^{32}$ Department of Clinical Medicine, Ruhr University, Bochum, Germany; ${ }^{33}$ Department of Endocrinology, University of Heidelberg, Heidelberg, Germany; ${ }^{34}$ Department of Internal Medicine, Charles University, Prague, Czech Republic; ${ }^{35}$ Institute of Public Health, Cambridge, UK; ${ }^{36}$ Department of Medicine, University Hospital, Graz, Austria; 37Royal Cornwall Hospital, Truro, UK; ${ }^{38}$ Department of Radiology and Nuclear Medicine, Free University, Berlin, Germany and ${ }^{39}$ Centre for Metabolic Bone Disease, Sheffield, UK

\begin{abstract}
The presence of a vertebral deformity increases the risk of subsequent spinal deformities. The aim of this analysis was to determine whether the presence of vertebral deformity predicts incident hip and other limb fractures. Six thousand three hundred and forty-four men and 6788 women aged 50 years and over
\end{abstract}

Correspondence and offprint requests to: Dr Terence W. O'Neill, ARC Epidemiology Research Unit, Stopford Building, University of Manchester, Manchester M13 9PT, UK. Fax: +44 (0) 1612755043. were recruited from population registers in 31 European centers and followed prospectively for a median of 3 years. All subjects had radiographs performed at baseline and the presence of vertebral deformity was assessed using established morphometric methods. Incident limb fractures which occurred during the follow- up period were ascertained by annual postal questionnaire and confirmed by radiographs, review of medical records and personal interview. During a total of 40348 person-years of follow-up, 138 men and 391 
women sustained a limb fracture. Amongst the women, after adjustment for age, prevalent vertebral deformity was a strong predictor of incident hip fracture, (rate ratio $(R R)=4.5 ; 95 \%$ CI 2.1-9.4) and a weak predictor of 'other' limb fractures $(\mathrm{RR}=1.6 ; 95 \%$ CI $1.1-2.4)$, though not distal forearm fracture $(\mathrm{RR}=1.0 ; 95 \% \mathrm{CI}$ 0.6-1.6). The predictive risk increased with increasing number of prevalent deformities, particularly for subsequent hip fracture: for two or more deformities, $\mathrm{RR}=7.2(95 \%$ CI 3.0-17.3). Amongst men, vertebral deformity was not associated with an increased risk of incident limb fracture though there was a nonsignificant trend toward an increased risk of hip fracture with increasing number of deformities. In summary, prevalent radiographic vertebral deformities in women are a strong predictor of hip fracture, and to a lesser extent humerus and 'other' limb fractures; however, they do not predict distal forearm fractures.

Keywords: Incidence; Limb fracture; Osteoporosis; Vertebral deformity; Vertebral osteoporosis

\section{Introduction}

There is clear evidence that the presence of a vertebral deformity increases the risk of future spine fractures [1]. Less is known, however, about the predictive risk of a vertebral deformity on future limb fractures and particularly the hip and wrist. Longitudinal studies in women with clinically apparent vertebral deformities suggest that these are associated with a subsequent increased risk of nonvertebral fractures including a 1.8to 3.8-fold increased risk of hip fracture [2-6]. Even higher risks are observed in men and women admitted to hospital following a vertebral fracture [7]. However, clinically apparent deformities represent about one third of all vertebral deformities and the extent to which these findings may be generalized is unclear [8]. One study suggested that individuals with severe radiographic spinal deformity had an increased risk of future nonvertebral fractures; however, the numbers of cases were small and the risk of the individual fracture types was not reported [9]. In a more recent American study among a large group of elderly women, radiographic vertebral deformity was associated with an increase in the risk of future hip and any nonvertebral fracture, though, after adjusting for age and BMD, no increase in the risk of future wrist fracture was observed [10]. To our knowledge there are no data from population studies about the relationship of radiographic vertebral deformity and the risk of subsequent limb fracture in men. A better understanding of the relationship between radiographic vertebral deformity and the risk of future types of limb fracture may enable more effective targeting of fracture intervention programs.

The aim of this analysis was to determine whether the presence of radiographic vertebral deformity predicts incident limb fracture in European men and women and to confirm whether the magnitude of any increased risk is similar at individual fracture sites.

\section{Subjects and Methods}

\section{Subjects}

The subjects included in this analysis were recruited for participation in the European Vertebral Osteoporosis Study (EVOS). The detailed methods have been described elsewhere [11]. In brief, men and women aged 50 years and over were recruited from population registers in 36 European centers. Stratified sampling was used with the aim of recruiting equal numbers of men and women in each of six 5-year age bands: 50-54 years, 55-59 years, 60-64 years, 65-69 years, 70-74 years, and 75 years and over. Subjects were contacted by letter of invitation which included information about the study. Those who consented to take part were interviewed using a structured interview which included questions about previous fragility fractures. Lateral spinal radiographs were performed. The radiographs were evaluated morphometrically by one of three observers and the presence of vertebral deformity determined using the McCloskey-Kanis method [12].

The subjects recruited in 29 of the EVOS centers have been followed prospectively by annual postal questionnaire, and in a further 3 by telephone or personal interview (European Prospective Osteoporosis Study, EPOS). Subjects were asked to record details of any fractures sustained in the intervening period, and to mark on a body manikin (included with the postal questionnaire) the site of any fractures. Fractures reported were confirmed at each of the participating centers by the principal investigator by review of radiographs, medical record or subject interview. In addition the investigator confirmed the site of the reported fracture. From these sources contemporary data to confirm or refute the occurrence and site of fracture were not available in $9 \%$ of cases. In these cases the site of fracture was determined from the area marked by the subject on the manikin [13]. Because of a low follow-up rate (in part a consequence of large-scale population mobility) the data from one center (Zagreb, Croatia) were excluded from this analysis. The data coordination for the study was in Manchester and Lubeck (Germany). Ethics approval was obtained centrally and at individual participating centers.

\section{Analysis}

Subjects contributed follow-up time (person-years) from the date of the baseline survey until limb fracture, death or the end of the study. Fractures were classified using the 9th edition of the International Classification of Diseases [14] into the following categories: hip (neck of femur), ICD code 820; distal forearm, ICD code 813; humerus, ICD code 812 ; 'other' limb, ICD codes 814 $817,821-826$. Cox regression analysis was used to 
assess the predictive risk of vertebral deformity on future limb fractures [15]. Analysis was undertaken looking initially at 'any' limb fracture and then separately by fracture site. In subjects who sustained more than one fracture of the same type, the time to the first fracture event was used in the analysis. Adjustments were made for age and subsequently for previous low-trauma fragility over the age of 50 years (yes/no). To determine whether there was a trend toward an increased risk of limb fracture with increasing numbers of vertebral deformities, the analyses were repeated after categorization of subjects by number of vertebral deformities (none/single/two or more) and a test of trend performed. All analyses were undertaken separately in men and women. The proportional hazards assumption underlying the Cox regression model was checked visually using Aalen plots [16]. Analyses were performed using the statistical package STATA [17].

\section{Results}

\section{Subjects}

Six thousand three hundred and forty-four men, mean age $64.2(\mathrm{SD}=8.4)$ years, and 6788 women, mean age $63.6(\mathrm{SD}=8.4)$ years, were followed for a median of 3 years (range $0.4-5.9$ years), a total of 40348 personyears of follow-up. As previously reported [12] the prevalence of vertebral deformity was similar in men and women $(11.7 \%$ vs $11.8 \%)$. Multiple vertebral deformities $(\geqslant 2$ deformities) were present in $3.4 \%$ of men and $3.8 \%$ of women. Compared with the men, a greater proportion of the women reported a history of previous fragility fracture (after age 50 years) $(13.2 \%$ vs $5.1 \%)$.

\section{Limb Fractures}

In total, 138 men and 391 women sustained a limb fracture during the follow-up period (Table 1). Of these,
Table 1. Number of subjects with incident limb fracture by sex

\begin{tabular}{lcc}
\hline & Men & Women \\
\hline Hip & $19(14 \%)$ & $28(7 \%)$ \\
Distal forearm & $32(23 \%)$ & $150(38 \%)$ \\
Humerus & $15(11 \%)$ & $43(11 \%)$ \\
'Other' limb & $74(53 \%)$ & $178(45 \%)$ \\
Any limb fracture $^{\mathrm{a}}$ & $138(100 \%)$ & $391(100 \%)$ \\
\hline
\end{tabular}

${ }^{a}$ Numbers in cells do not add up because 10 subjects incurred more than one type of limb fracture.

the majority were fractures of the distal forearm. Ten subjects sustained more than one type of limb fracture.

\section{Vertebral Deformity and Incident Limb Fractures}

Table 2 presents the crude and age-adjusted rate ratios (RR) for the association between baseline prevalent vertebral deformity and future limb fracture in men and women. Among women, after age adjustment, those with a prevalent vertebral deformity had a modestly increased risk of sustaining 'any' limb fracture: rate ratio $(\mathrm{RR})=$ $1.6(95 \%$ confidence interval (CI) 1.2-2.1). In contrast, among men, there was no association between baseline deformity and subsequent 'any' limb fracture: $R R=1.0$ (95\% CI 0.6-1.7).

In women, prevalent vertebral deformity was associated with a significant increase in the risk of subsequent hip fracture: $(\mathrm{RR}=4.5 ; 95 \%$ CI $2.1-9.4)$, a weak increase in the risk of 'other' limb fractures ( $R R=$ 1.6 ; 95\% CI 1.1-2.4) and a weak though nonsignificant increase in the risk of humerus fracture $(\mathrm{RR}=1.6 ; 95 \%$ CI $0.7-3.3)$. Thirty-six per cent of women with hip fracture had a baseline vertebral deformity. There was no association with distal forearm fracture. In men, prevalent vertebral deformity was associated with a weak though nonsignificant increase in the risk of hip fracture $(\mathrm{RR}=1.7 ; 95 \%$ CI $0.6-5.1)$. There was no

Table 2. Relationship between prevalent vertebral deformity and incident limb fracture in men and women

\begin{tabular}{|c|c|c|c|c|c|c|c|c|}
\hline \multirow{3}{*}{ Limb fracture } & \multicolumn{4}{|l|}{ Men } & \multicolumn{4}{|l|}{ Women } \\
\hline & \multicolumn{2}{|c|}{ Baseline vertebral deformity } & \multirow[b]{2}{*}{$\begin{array}{l}\text { Rate ratio, } \\
\text { crude } \\
(95 \% \mathrm{CI})\end{array}$} & \multirow[b]{2}{*}{$\begin{array}{l}\text { Rate ratio, } \\
\text { age-adjusted } \\
(95 \% \mathrm{CI})\end{array}$} & \multicolumn{2}{|c|}{ Baseline vertebral deformity } & \multirow[b]{2}{*}{$\begin{array}{l}\text { Rate ratio, } \\
\text { crude } \\
(95 \% \mathrm{CI})\end{array}$} & \multirow[b]{2}{*}{$\begin{array}{l}\text { Rate ratio, } \\
\text { age-adjusted } \\
(95 \% \mathrm{CI})\end{array}$} \\
\hline & $\begin{array}{l}\text { No } \\
(n=5601) \\
n(\%)^{\mathrm{a}}\end{array}$ & $\begin{array}{l}\text { Yes } \\
(n=743) \\
n(\%)^{\mathrm{b}}\end{array}$ & & & $\begin{array}{l}\text { No } \\
(n=5989) \\
n(\%)^{\mathrm{a}}\end{array}$ & $\begin{array}{l}\text { Yes } \\
(n=799) \\
n(\%)^{\mathrm{b}}\end{array}$ & & \\
\hline Hip & $15(0.3 \%)$ & $4(0.5 \%)$ & $2.0(0.7-6.2)$ & $1.7(0.6-5.1)$ & $15(0.3 \%)$ & $13(1.6 \%)$ & $6.6(3.2-13.9)$ & $4.5(2.1-9.4)$ \\
\hline Distal forearm & $29(0.5 \%)$ & $3(0.4 \%)$ & $0.8(0.2-2.6)$ & $0.8(0.2-2.6)$ & $131(2.2 \%)$ & $19(2.4 \%)$ & $1.1(0.7-1.8)$ & $1.0(0.6-1.6)$ \\
\hline Humerus & $15(0.3 \%)$ & 0 & $\dagger$ & $\dagger$ & $34(0.6 \%)$ & $9(1.1 \%)$ & $2.0(1.0-4.2)$ & $1.6(0.7-3.3)$ \\
\hline Other limb & $65(1.2 \%)$ & $9(1.2 \%)$ & $1.2(0.5-2.1)$ & $1.2(0.6-2.4)$ & $146(2.4 \%)$ & $32(4.0 \%)$ & $1.7(1.1-2.4)$ & $1.6(1.1-2.4)$ \\
\hline Any limb & $122(2.2 \%)$ & $16(2.2 \%)$ & $1.0(0.6-1.7)$ & $1.0(0.6-1.7)$ & $318(5.3 \%)$ & $73(9.1 \%)$ & $1.8(1.4-2.3)$ & $1.6(1.2-2.1)$ \\
\hline
\end{tabular}

\footnotetext{
${ }^{\mathrm{a}}$ Number and percentage of individuals without vertebral deformity with individual limb fracture type

${ }^{\mathrm{b}}$ Number and percentage of individuals with vertebral deformity with individual limb fracture type.

†Too few events.
} 
Table 3. Relationship between number of prevalent vertebral deformities and incident limb fracture in men and women

\begin{tabular}{|c|c|c|c|c|c|c|c|c|c|c|}
\hline & \multicolumn{5}{|c|}{$\begin{array}{l}\text { Men } \\
\text { Rate ratio }(95 \% \mathrm{CI})\end{array}$} & \multicolumn{5}{|c|}{$\begin{array}{l}\text { Women } \\
\text { Rate ratio }(95 \% \mathrm{CI})\end{array}$} \\
\hline & Hip & $\begin{array}{l}\text { Distal } \\
\text { forearm }\end{array}$ & Humerus & Other & $\begin{array}{l}\text { 'Any' } \\
\text { limb }\end{array}$ & Hip & $\begin{array}{l}\text { Distal } \\
\text { forearm }\end{array}$ & Humerus & Other & $\begin{array}{l}\text { ‘Any' } \\
\text { limb }\end{array}$ \\
\hline $\begin{array}{l}\text { No vertebral } \\
\text { deformity }\end{array}$ & 1.0 & 1.0 & 1.0 & 1.0 & 1.0 & 1.0 & 1.0 & 1.0 & 1.0 & 1.0 \\
\hline $\begin{array}{l}1 \text { vertebral } \\
\text { deformity }\end{array}$ & $\begin{array}{l}1.2 \\
(0,3-5,4)\end{array}$ & $\begin{array}{l}0.7 \\
(0.2-3.1)\end{array}$ & $\dagger$ & $\begin{array}{l}0.9 \\
(0.4-2.2)\end{array}$ & $\begin{array}{l}0.8 \\
(0.4-16)\end{array}$ & $\begin{array}{l}2.8 \\
(1.0-7.7)\end{array}$ & $\begin{array}{l}0.9 \\
(0.5-1.6)\end{array}$ & $\begin{array}{l}1.2 \\
(0.3-5.4)\end{array}$ & $\begin{array}{l}1.3 \\
(0.8-2.2)\end{array}$ & $\begin{array}{l}1.2 \\
(09-17)\end{array}$ \\
\hline $\begin{array}{l}2+\text { vertebral } \\
\text { deformities }\end{array}$ & $\begin{array}{l}2.7 \\
(0.6-11.7)\end{array}$ & $\begin{array}{l}0.9 \\
(0.1-6.4)\end{array}$ & $\dagger$ & $\begin{array}{l}1.9 \\
(0.7-5.1)\end{array}$ & $\begin{array}{l}1.5 \\
(0.7-3.3)\end{array}$ & $\begin{array}{l}7.2 \\
(3.0-17.3)\end{array}$ & $\begin{array}{l}1.2 \\
(0.6-2.6)\end{array}$ & $\begin{array}{l}2.7 \\
(0.6-11.7)\end{array}$ & $\begin{array}{l}2.4 \\
(1.4-4.1)\end{array}$ & $\begin{array}{l}2.4 \\
(1.7-3.4)\end{array}$ \\
\hline & & $p=0.7$ & - & $p=0.4$ & & & & & & \\
\hline
\end{tabular}

${ }^{\mathrm{a} A d j u s t e d ~ f o r ~ a g e . ~}{ }^{\mathrm{b}}$ Individuals without prevalent vertebral deformity form the referent group in all analyses.

${ }^{\dagger}$ Too few events.

increase in the risk of any of the other limb fracture types in men.

Adjustment for previous low-trauma fractures slightly reduced the strength of the association between vertebral deformity and subsequent hip fracture in women $(\mathrm{RR}=$ $4.2 ; 95 \%$ CI $2.0-9.0)$ and in men ( $\mathrm{RR}=1.6 ; 95 \%$ CI 0.5 4.9), though it did not influence the strength of the associations for the other fracture types (data not shown).

\section{Influence of Number of Vertebral Deformities}

In both sexes, increasing number of vertebral deformities was associated with an increased risk of all types of limb fracture except distal forearm fracture (Table 3). The increase in risk was greatest for hip fracture and more marked in women than in men $(2+$ deformities vs no deformity: women $\mathrm{RR}=7.2 ; 95 \%$ CI 3.0-17.3, and men $\mathrm{RR}=2.7 ; 95 \%$ CI $0.6-11.7$ )

\section{Discussion}

In this prospective study, radiographic vertebral deformities in women predicted hip fracture and to a lesser extent humerus and 'other' limb fracture, though not distal forearm fracture. In men there was a weak though statistically nonsignificant association with hip fracture only.

There are relatively few data concerning the relationship between radiographic vertebral deformity and future limb fracture. Vertebral fractures which come to clinical attention are associated with a 2 - to 3 -fold increased risk in future fragility fractures including a 1.8 - to 3.8 -fold risk of sustaining a hip fracture [2-6]. Such clinically apparent fractures, however, account for about one third of all vertebral fractures [8], and the extent to which these findings may be generalized beyond this group is unclear. In a population-based study, Burger et al. [9] found that subjects with severe radiographic vertebral deformity had an increased risk of future nonvertebral fractures; however, the numbers of subjects were small and the future risk of individual fracture types was not reported [9]. Fujiwara et al. [18] in a Japanese cohort reported a 2-fold increased risk of hip fracture associated with prevalent vertebral deformities. In a more recent large study of elderly American women, radiographic vertebral deformity was associated with an increased risk of hip and any nonvertebral fracture, with relative risks of 2.8 and 1.9 respectively [10]. In contrast, after adjusting for age and BMD no increased risk was observed for wrist fracture [10]. Our data confirm these findings with an increased risk of hip and 'any' limb, though not wrist fracture, in a cohort of younger European women though the magnitude of the increased risk of hip fracture was greater than that observed in the American study.

What is the mechanism by which prevalent vertebral deformity increases the risk of future hip and other limb fractures? At least part of the explanation is that both fractures share similar underlying risk factors and in particular a reduction in bone mass [19-21]. In previous studies, however, the predictive risk of future nonvertebral fractures remained significant after adjusting for bone mass suggesting that other factors are also important $[9,10]$. In our study bone mass measurements were performed in a subsample (28\%) of the study cohort. When we looked at 'any' limb fracture in this sub sample, adjusting for BMD did not alter the strength of the observed associations. Poor bone quality, or an increased tendency to fall among those with prevalent vertebral deformity, may in part explain the increase in risk. Further studies are required in order to tease out the relative contribution of bone mass, quality and falls in explaining the increased risk.

In our study vertebral deformity did not predict future distal forearm fracture. It is possible that individuals who sustain a vertebral deformity may, because of symptoms (e.g., back pain), fear of falling or co-morbid factors, become less mobile and therefore in a fall are less likely to fall forward onto their outstretched hand and thus be less likely to sustain a distal forearm fracture [22]. Adjusting for time spent walking did not influence our findings, though it may be that other parameters of 
physical activity such as walking frequency or speed, which were not assessed in our study, may be important $[23,24]$.

We found no association between prevalent vertebral deformity and incident limb fractures in men. We have shown previously that very heavy activity undertaken during occupational or recreational life is linked with an increased risk of vertebral deformity - suggesting that trauma may be a factor in their pathogenesis [25]. The presence of multiple deformities is a stronger indicator of underlying osteoporosis than a single vertebral deformity [26] and this may explain the modest (though nonsignificant) increased risk of hip fracture which was observed in men with multiple deformities. Another possible reason for the absence of any significant associations is that compared with women a greater proportion of limb fractures in men are related to moderate or heavy trauma rather than osteoporosis $[27,28]$.

Our study had several advantages: it was prospective, population-based and included both men and women. There are, however, several limitations which need to be considered when interpreting the results. This was a multicenter study and investigators were separately responsible for confirming the presence and site of self-reported fractures at their individual centers. It is possible errors may have arisen during this process resulting in misclassification of either fracture status or fracture type. It is likely, however, that the effect of any such misclassification would be random and tend to reduce the strength of the observed risks between vertebral deformity and subsequent limb fracture. Misclassification may also have arisen if incident limb fractures which occurred were not reported. The effect of such misclassification would again be to reduce the chance of finding significant associations. In a separate study at three of the participating centers, amongst 174 subjects with a known history of previous fracture, only $12(7 \%)$ did not recall the event, and only $3 \%$ of subjects did not recall a hip or distal forearm fracture [13].

In $9 \%$ of fracture cases information about the presence and site of the fracture was available only from the postal questionnaire. This was in part due to inherent difficulties in access to radiographs and medical records that exist in some European countries. In some countries, for example, casualty radiographs are not routinely reported and individuals are permitted to keep their radiographs. The data on these self-reports is likely to be less accurate than reports which were confirmed. In EPOS, of those in whom verification of fracture was possible, fractures were not confirmed in $11 \%$, though the proportion was lower for hip and wrist fractures [13]. However, restricting the analyses to those individuals in whom fractures were confirmed did not affect the results (data not shown).

In this analysis vertebral deformity was defined using a morphometric approach [12]. This approach does not distinguish between deformities due to osteoporosis and deformities due to other causes including osteoarthrosis and trauma. Previous studies, however, suggest a relatively strong association between a reduction in bone mass and morphometrically defined vertebral deformity in women and men, suggesting that osteoporosis is important in their pathogenesis in both sexes [19]. The inclusion of non-osteoporotic deformities would be likely to tend to reduce the chance of finding significant associations with future fractures. Certain deformity types appear to be more strongly associated with low bone mass than others; however, the numbers in our study were too small to permit stratification by individual deformity type [19].

Our data have important clinical and public health considerations. The results highlight the important predictive risk of radiographic vertebral deformity for future hip fracture, and also the aetiologic heterogeneity of the different fracture types. Hip fracture is the major consequence of osteoporosis with significant morbidity and economic impact [29]. Vertebral fractures occur at an earlier age than hip fracture. Early identification and targeting interventions at such individuals may help to reduce the burden of morbidity due to hip fracture in later life.

In summary, we have shown that future limb fractures and particularly hip fracture are an important health outcome in women with prevalent vertebral deformities. Our data also highlight the aetiologic heterogeneity of the different fracture types.

Acknowledgements. The study was financially supported by a European Union Concerted Action Grant under Biomed-1 (BMH1CT920182), and also EU grants C1PDCT925102, ERBC1PDCT 930105 \& 940229. The central coordination was also supported by the UK Arthritis Research Campaign, the Medical Research Council (G9321536) and the European Foundation for Osteoporosis and Bone Disease. Individual centers acknowledge the receipt of locally acquired support for their data collection. Dr Abbas Ismail was a Wellcome Trust Clinical Research Fellow. We would like to thank the following individuals for practical assistance: Aberdeen, UK: Rita Smith; Cambridge \& Harrow, UK: Anna Martin, Judith Walton; Truro, UK: Mrs Joanna Parsons; Oviedo, Spain: Manuel Naves Diaz, J. Bernardino Diaz Lopez, Ana Rodriguez Rebollar; Madrid, Spain: M. Diaz Curiel, J. Ortega.

\section{References}

1. Ross PD, Davis JW, Epstein RS, Wasnich RD. Pre-existing fractures and bone mass predict vertebral fracture incidence in women. Ann Intern Med 1991;114:919-23.

2. Gärdsell $\mathrm{P}$, Johnell $\mathrm{O}$, Nilsson $\mathrm{B}$, Nilsson J. The predictive value of fracture, disease, and falling tendency for fragility fractures in women. Calcif Tissue Int 1989;45:327-30.

3. Melton LJ, Atkinson EJ, Cooper C, O'Fallon WM, Riggs BL. Vertebral fractures predict subsequent fractures. Osteoporos Int 1999;10:214-21.

4. Lauritzen JB, Lund B. Risk of hip fracture after osteoporosis fractures. Acta Orthop Scand 1993;64:297-300.

5. Kotowicz MA, Melton LJ III, Cooper C, Atkinson EJ, O'Fallon WM, Riggs, BL. Risk of hip fracture in women with vertebral fracture. J Bone Miner Res 1994;9:599-605.

6. Gunnes M, Mellstrom D, Johnell O. How well can a previous fracture indicate a new fracture? Acta Orthop Scand 1998;69:508-12.

7. Johnell O, Oden A, Kanis JA, Caulin F. Increased risk of further fractures after hospitalisation for vertebral fractures: a prospective study. J Bone Miner Res 1998;13 (Suppl 5):S152. 
8. Cooper C, Atkinson EJ, O'Fallon WM, Melton LJ III. Incidence of clinically diagnosed vertebral fractures: a population based study in Rochester, Minnesota, 1985-1989. J Bone Miner Res 1992;7:221-7.

9. Burger H, van Daele PLA, Algra D, Hofman A, Grobbee DE, Schütte HE, et al. Vertebral deformities as predictors of nonvertebral fractures. B M J 1994;309:991-2.

10. Black DM, Arden NK, Palermo L, Pearson J, Cummings SR, for the Study of Osteoporotic Fractures Research Group. Prevalent vertebral deformities predict hip fractures and new vertebral deformities but not wrist fractures. J Bone Miner Res 1999;14:821-8.

11. O'Neill TW, Felsenberg D, Varlow J, Cooper C, Kanis JA, Silman AJ, and the European Vertebral Osteoporosis Study Group. The prevalence of vertebral deformity in European men and women: the European Vertebral Osteoporosis Study. J Bone Miner Res 1996;11:1010-8.

12. McCloskey EV, Spector TD, Eyres KS, Fern ED, O'Rourke N, Vasikaran S, et al. The assessment of vertebral deformity: a method for use in population studies and clinical trials. Osteoporos Int 1993;3:138-47.

13. Ismail AA, O'Neill TW, Cockerill W, Finn JD, Cannata JB, Hoszowski K, et al., and the EPOS Study Group. Validity of self report of fractures: results from a prospective study in men and women across Europe. Osteoporos Int 2000;11:248-54.

14. World Health Organization. International statistical classification of diseases and related health problems. 9th ed. Geneva: World Health Organization, 1978.

15. Cox DR. Regression models and life tables. J R Stat Soc B 1972;34:187-220.

16. Kalbfleisch JD, Prentice RL. The statistical analysis of failure time data. New York: Wiley, 1980

17. Stata Corporation. Stata reference manual, release 3.1. 6th ed. College Station, TX: Stata Corporation.

18. Fujiwara S, Kasagi F, Yamada M, Kodama K. Risk factors for hip fracture in a Japanese cohort. J Bone Miner Res 1997;12:9981004.

19. Lunt M, Felsenberg D, Reeve J, Benevolenskaya L, Cannata J,
Dequeker J, et al. Bone density variation and its effects on risk of vertebral deformity in men and women studied in thirteen european centres: the EVOS study. J Bone Miner Res 1997; 12:1883-94.

20. Marshall D, Johnell O, Wedel H. Meta-analysis of how well measures of bone mineral density predict occurrence of osteoporotic fractures. BMJ 1996;312:1254-9.

21. Seeley DG, Browner WS, Nevitt MC, Genant HK, Scott JC, Cummings SR, for the Study of Osteoporotic Fractures Research Group. Which fractures are associated with low appendicular bone mass in elderly women? Ann Intern Med 1991;115: 837-42.

22. Nevitt MC, Cummings SR, and the Study of Osteoporotic Fracture Research Group. Type of fall and risk of hip and wrist fractures: the Study of Osteoporotic Fractures. J Am Geriatr Soc 1993;41:1226-34.

23. Kelsey JL, Browner WS, Seeley DG, Nevitt MC, Cummings SR, for the Study of Osteoporotic Fractures Research Group. Risk factors for fractures of the distal forearm and proximal humerus. Am J Epidemiol 1992;135: 477-89.

24. O’Neill TW, Marsden D, Adams JE, Silman AJ. Risk factors, falls, and fracture of the distal forearm in Manchester, UK. J Epidemiol Community Health 1996;50:288-92.

25. Silman AJ, O'Neill TW, Cooper C, Kanis J, Felsenberg D, and the European Vertebral Osteoporosis Study Group. Influence of physical activity on vertebral deformity in men and women: results from the European Vertebral Osteoporosis Study. J Bone Miner Res 1997;12:813-9.

26. Ismail AA, O'Neill TW, Cooper C, Silman AJ, and the European Vertebral Osteoporosis Study Group. Risk factors for vertebral deformities in men: relationship to number of vertebral deformities. J Bone Miner Res 2000;15:278-83.

27. Knowleden J, Buhr AJ, Dunbar O. Incidence of fractures in persons over 35 years of age. Br J Prev Soc Med 1964;18:130-41.

28. Garraway WM, Stauffer RN, Kurland LT, O'Fallon WM. Limb fractures in a defined population. I. Frequency and distribution. Mayo Clin Proc 1997;54:701-7.

29. Cooper C, Melton LJ III. Epidemiology of osteoporosis. Trends Endocrinol Metab 1992;3:224-9. 